\title{
Policy Document on Evaluation of Student Outcomes, Program Intended Learning Outcomes and Faculty Loading in Higher Quality Accredited Institutions
}

\author{
Christo Ananth ${ }^{1}$ \\ College of Engineering, AMA International University, Bahrain ${ }^{1}$
}

\begin{abstract}
This Policy report guarantee that all its Program contributions are fit-for-reason and that its alumni have the information, aptitudes and capabilities expected upon fruitful finish of their Program, through an intermittent appraisal and assessment of explicit Student Outcomes and Program Intended Learning Outcomes laid out for each Program. The Policy Document necessitates that appraisal and assessment of understudy results are done toward the finish of every semester. Understudy Outcomes and Program Intended Learning Outcomes are evaluated utilizing the accompanying strategies, if pertinent: 1) direct appraisal by the staff for chosen courses; 2) senior leave review; 3) evaluation of the Student Outcomes and Program Intended Learning Outcomes for terminal task/look into undertaking course(s); 4) self assessment overview on Student Outcomes and Program Intended Learning Outcomes by the understudies; and 5) understudy's practicum boss' assessment of the Student Outcomes and Program Intended Learning Outcomes
\end{abstract}

Keywords: Higher Quality Accredited Institutions, Teaching, Learning \& Assessment, Student Outcomes, Course Intended Learning Outcomes, Program Intended Learning Outcomes

\section{INTRODUCTION}

The Department Head is in charge of doling out personnel Document guarantees that all classes offered in like manner loads, in agreement to the University guidelines. Partner for the term have doled out employees from the main day of Dean surveys the personnel stacking and underwrites to the class up to the finish of the term. Employees doled out to Dean. The Dean supports the personnel stacking for the term in their individual offices. The Overall Academic Dean is in charge of Consistent and proficient execution of this strategy and systems. the Placement, Linkage and Alumni Office, cooperates with the College Committee for Student Outcomes and Program Intended Learning Outcomes Assessment and Evaluation, in get-together required information through practicum competency-based assessment by the understudy's chief in the organization where the understudy embraces the hands on preparing. The Guidance Office regulates the senior exit reviews toward the finish of the last semester of the understudy in the college. The College Committee for Student Outcomes and Program Intended Learning Outcomes Assessment and Evaluation is in charge of merging and examining information gathered from these different appraisal strategies. The Policy convey the course should have the required certifications, capabilities and ability to instruct and deal with the doled out courses. The Policy Document covers both full-and low maintenance employees, who are incorporated into the Human Resource Development-affirmed synopsis list. Also, this will cover the non-scholastic full-time representatives with showing certifications, capabilities and ability who is given educating load(s) after available time, at a most extreme heap of three (3) credit hours seven endless supply of concerned heads and the University President.

\section{ASSESSMENT PROCEDURE}

Appraisal by staff from the chose courses is submitted toward the finish of every Semester utilizing the appraisal and assessment formats. Every employee presents a Course Intended Learning Outcome report to the College Committee in regards to the evaluation of the Course Intended Learning 


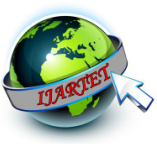

International Journal of Advanced Research Trends in Engineering and Technology (IJARTET) Vol. 5, Issue 4, April 2018
Outcomes. The employees utilize different appraisal Program Intended Learning Outcomes, which is made out of techniques, to decide the achievement of the particular Student Outcomes and Program Intended Learning Outcomes mapped to their courses. Every school builds up the fitting Student Outcomes and Program Intended Learning Outcomes device which is utilized as reason for the PILOs assessment.

The Guidance Office oversees a Senior Exit Survey to the graduating understudies during their last semester of the program. The aftereffects of the review are submitted to the school board of trustees for Student Outcomes and Program Intended Learning Outcomes Assessment and Evaluation for fuse to the general fulfillment of Student Outcomes and Program Intended Learning Outcomes. Appraisal of understudy results for capstone venture/postulation course(s) is finished by the Review Panel comprising of 2 interior inspectors and 1 outside analyst) who sits as evaluators during the introduction and barrier of the undertaking. The employee taking care of the capstone/theory course presents a competency-based appraisal to the College Committee for Student Outcomes and Program Intended Learning Outcomes Assessment and Evaluation toward the finish of the semester for fuse to the general fulfillment of Student Outcomes and Program Intended Learning Outcomes. Prior as far as possible of every semester, understudies took a crack at chosen proficient courses round out a selfassessment study surveying the achievement of the SOs/PILOs for that specific course. Employees taking care of said course present the overview report to the College Committee for Student Outcomes and Program Intended Learning Outcomes Assessment and Evaluation toward the finish of the trimester for fuse to the general achievement of Student Outcomes and Program Intended Learning Outcomes. The understudy's Company Supervisor achieves a competency put together assessment structure with respect to the understudies' accomplishment of Student Outcomes and Program Intended Learning Outcomes. The Practicum course organizer presents the outcome to the College Committee for Student Outcomes and Program Intended Learning Outcomes Assessment and Evaluation toward the finish of the trimester for joining to the general accomplishment of Student Outcomes and Program Intended Learning Outcomes.

\section{EVALUATION PROCEDURES}

The assessment of the Student Outcomes and Program Intended Learning Outcomes lays on the College Committee for Assessment and Evaluation of Student Outcomes and employees of the particular program. The totaled information from the evaluation techniques recorded above are utilized by the board in finishing up whether the understudy results are effectively achieved. The school panel for Assessment and Evaluation of Student Outcomes submits reports to the Dean. The Dean assesses the report and considers the investigation as a feature of persistent improvement in a joint effort with the Curriculum Review Committee and the Committee for Continuous Quality and Improvement. Quality Record incorporates Course Intended Learning Outcomes Evaluation Report, Senior Exit Survey Report, Practicum Evaluation Report, Self-Evaluation by Student Report, Student Outcomes and Program Intended Learning Outcomes Committee Report. This information is disseminated to Overall Academic Dean, Deans of Colleges, Head of Quality Assurance and Accreditation, Head of Guidance, Head of Placement Linkages and Alumni and College Committee of Student Outcomes and Program Intended Learning Outcomes Evaluation

\section{FACULTY LOADING PROCEDURES}

Partner Deans and Department Heads group all the required references for personnel stacking, for example, course contributions, rundown of employees, and workforce specialization.

At any rate seven days before the beginning of classes, the Department Head doles out every single normal class to fulltime employees, which comprise of in any event eight enrolled understudies. The provisional stacking must be endorsed by the Dean. The bases and criteria of allocating staff load assignments incorporate the field of specialization, execution rating, rank and grouping, look into capacities and the Higher Education Board stacking strategy where: Professors will have 9 credit hour of instructing, Associate Professor will have 12 credit long periods of instructing, Assistant Professor and Lecturers will have 15 credit long stretches of educating. The encouraging burden determined will be decreased by 3 credit hours ( 1 course) for employees doled out with authoritative duties (for example Dignitary, Associate Dean, Department Head). Expert and propelled courses are relegated and ideally stacked to Doctoral qualification holders or to Master qualification holders with expert accreditations. The Associate Dean pursues intently the enlistment of the understudies during the Add/Drop period to ensure that all the affirmed segments are appointed to an accessible employee (Part or full time). The Dean's 


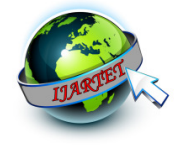

International Journal of Advanced Research Trends in Engineering and Technology (IJARTET) Vol. 5, Issue 4, April 2018

office guarantees that the last personnel stacking is encoded in the Course Information System. The Dean's Office submits to concerned workplaces the last workforce stacking of his/her school to the workplaces, for example, the Overall Sub-Academic Dean for Academic Affairs, Human Resource, Research Office and Quality Assurance and Accreditation Office. Quality Records incorporate Faculty Loading, Faculty load/plotting structure endorsed by the Dean recognized by Human Resource Development. This information is dispersed to Overall Academic Dean, Audit, Faculty and Department Heads

\section{Conclusion}

This Policy report reasons that all its Program contributions are fit-for-reason and that its alumni have the information, abilities and skills expected upon effective finish of their Program, through an occasional appraisal and assessment of explicit Student Outcomes and Program Intended Learning Outcomes delineated for each Program. The Policy Document necessitates that appraisal and assessment of understudy results are done toward the finish of every semester. Understudy Outcomes and Program Intended Learning Outcomes are evaluated utilizing the accompanying techniques, if material: 1) direct appraisal by the staff for chosen courses; 2) senior leave study; 3) evaluation of the Student Outcomes and Program Intended Learning Outcomes for terminal task/inquire about venture course(s); 4) self assessment overview on Student Outcomes and Program Intended Learning Outcomes by the understudies; and 5) understudy's practicum director's assessment of the Student Outcomes and Program Intended Learning Outcomes.

\section{REFERENCES}

[1] Cushing, C. (2002). A reflection on developing a consistency of teacher judgement process. Curriculum Matters, 1(3), 10.

[2] Cushman, K. (1996). Looking collaboratively at student work: An essential toolkit. Horace, 13(2).

[3] Department of Education Tasmania. (25 August 2005). Professional learning: Protocols. Retrieved November 3, 2006, from http://www.ltag.education.tas.gov.au/Proflearn/commlearn/protocols. htm

[4] Dompnier, B., Pansu, P., \& Bressoux, P. (2006). An integrative model of scholastic judgements: Pupils' characteristics, class context, halo effect and internal attributions. European Journal of Psychology of Education, 21(2), 119-133.

[5] Forster, M. (2006). Assessment and reporting: What do we need to understand? Professional Voice, 4(2), 21-25.
[6] Freebody, P. P. (2005). Background, rationale and specifications: Queensland curriculum, assessment and reporting framework: Department of Education and the Arts, Queensland Government.

[7] Garcia, J., \& Rothman, R. (2002). Three paths, one destination: Standards-based reform in Maryland, Massachusetts and Texas. Washington DC: Achieve Inc.

[8] Gipps, C. (1994). Beyond testing: Towards a theory of educational assessment. London: The Falmer Press.

[9] Gipps, C., \& Clarke, S. (1998). Monitoring consistency in teacher assessment and the impact of SCAA 's guidance materials at key stages 1, 2, and 3: Final report. London: QCA.

[10] Guskey, T. R. (2001). Helping standards make the grade. Educational Leadership, 59(1), 20-27. 